\title{
A hybrid FCM-AHP approach to predict impacts of offshore outsourcing location decisions on supply chain resilience
}

\author{
Cristina Lópeza \\ University Pablo of Olavide, Department of Management and Marketing, Pedro R. \\ Campomanes Building, Road Utrera, km. 1, 41013 Seville, Spain

\begin{abstract}
Alessio Ishizakab
University of Portsmouth, Portsmouth Business School, Richmond Building, Portland

Street, Portsmouth PO1 3DE, United Kingdom
\end{abstract}

\begin{abstract}
:
The on-going offshore outsourcing processes have resulted in complex, global and more vulnerable supply chain to disruptions. However, a good supplier choice would preserve or even improve supply chain resilience. Despite this critical potential effect, this topic remains relatively underdeveloped in the literature. Accordingly, this study proposes a coupled method based on FCM and AHP. The final model shows the impact of locational decision in offshore outsourcing process on supply chain resilience. Moreover, it allows simulating locations scenarios over time through an inference process. The simulations foresee the impacts of three alternative locations on capabilities required in a resilient supply chain. The sensitivity analysis of the findings reveals that one location would improve supply chain resilience meanwhile the others would damage it. This FCM-AHP analysis enhances the understanding of academics and practitioners about the importance of locations criteria and their influence in the supply chain resilience capabilities.
\end{abstract}

Keywords: Location criteria; Supply Chain resilience capabilities; offshore outsourcing decisions; FCM; AHP. 


\section{Introduction}

Offshore outsourcing process is one of the most adopted strategy in the current and globalized business world. It allows firms to focus on core competencies, to improve their productivity, to gain in efficiency, effectiveness and flexibility, to share risk, to access to specialized resources, to enter into new markets and to a large extent, achieve cost savings. Although promising, this technique is not a panacea to handle all enterprise today-concerns. In fact, outsourcing can add new threats, often unrecognized hazards to the client firms (Johnson, 2006; Kishore \& Herath, 2010; Nakatsu \& lacovou, 2009), and by extension, in their supply chains (SC).

Offshore outsourcing implies to transfer ownership business activities and/or processes to low-cost providers outside of the client company country of origin (Hätönen, 2009; Lahiri \& Kedia, 2011). The central following question is "where to outsource". In fact, the provider selected will be a new player in the ever increasing integrated SC. According to Rice \& Caniato (2003), 'the supply network is inherently vulnerable to disruptions and the failure of any one element in it could cause the whole network to fail'. Therefore, an incorrect choice would lead to a very negative repercussion on the entire network.

Offshore outsourcing location decisions would affect the business profitability of client firms, as well as their market position (Gylling, Heikkilä, Jussila, \& Saarinen, 2015). However, in many cases, executives have scarce information and limited time to make decisions. In addition, a great variety of criteria should be considered to assess the available alternatives, which largely exceed the humans' cognitive ability. Multi-criteria decision making approaches have been widely used to assess available alternatives (Lin, Wang, \& Qin, 2007; Liu, Berger, Zeng, \& Gerstenfeld, 2008). However, each alternative entails hidden risks (Hätönen, 2009), which have not been considered in previous researches. 
Nowadays the adoption of lean and agile thinking, globalization and offshore outsourcing processes have contributed to make SC more vulnerable (Carvalho, Barroso, Machado, Azevedo, \& Cruz-Machado, 2012; Kamalahmadi \& Parast, 2016; Ponomarov \& Holcomb, 2009). Most of client firms have already offshored core competencies to suppliers globally dispersed, focusing their efforts on selected key value creating competences. This trend has resulted in a growing SC complexity and interdependency between their entities, which explains the rise of SC vulnerability leading to more frequent disruptions (Rezapour, Farahani, \& Pourakbar, 2016; Zeng \& Yen, 2016).

A recent study exposes the effects of the Tohoku earthquake (happened in Japan 2011) in Toyota and most of their suppliers (Matsuo, 2015). It stresses the importance of collaborating between SC players to recover to the normal activity. Therefore, certain capabilities can improve SC resilience against unexpected disruptions. More specifically, a resilient SC is capable of anticipating and minimizing negative effects of disruptions, as well as significantly reducing the recovery time needed to return to the normal activity or even to a better state (Blackhurst, Dunn, \& Craighead, 2011; Christopher \& Peck, 2004; Pettit, Fiksel, \& Croxton, 2010; Rice \& Caniato, 2003). It is argued that a resilient firm may improve its competitive position and the responsive capability of its SC (Sheffi \& Rice Jr, 2005). Hence, SC resilience has been considered an important issue in the location decision making process (Bailey \& De Propris, 2014). In spite of this, literature has made little efforts in examining the links between locational decision in offshore outsourcing process and SC resilience. 
By focusing on preserving or improving SC resilience from offshore outsourcing location decision-making, this study proposes a combined approach based on Fuzzy Cognitive Maps (FCM) and Analytic Hierarchy Process (AHP). FCM is capable of representing all possible causal connections between criteria considered to assess alternative location, together with capabilities identified in resilient SCs. It has also the ability to deal with uncertain and imprecise data by using fuzzy weights. Likewise, FCM can foresee the impact of alternative locations on SC resilience by simulating scenarios over time.

FCM has also disadvantages. The main difficulty is to assign the weight to the casual links. Some researchers have used a linguistic evaluation (Mourhir et al., 2015; Obiedat \& Samarasinghe, 2016). However, the difficulty is only shifted because the question remains on how to translate a linguistic evaluation into a quantitative evaluation. In this paper, we propose to overcome this transformation disadvantage with a new method based on AHP (Ishizaka \& Labib, 2011; Saaty, 1980).

The rest of the paper sets the background of the study in section 2 . The methodology is described in section 3. Section 4 presents a real case study and Section 5 concludes the paper.

\section{Background}

\subsection{Locational decision in offshore outsourcing process}

Location selection has a strategic importance for companies searching to increase their competitiveness, performances and efficiency. However, an erroneous location may cause drawbacks as for example higher transportation costs, loss of qualified labour and difficult administrative processes. Therefore, choosing a suitable location for outsourcing activities is a complex issue that requires a careful and combined analysis of numerous criteria. Vestring, Rouse, \& Reinert (2005) claim that each location has its own strengths and weaknesses, therefore a portfolio of locations should be selected to spread the risk. They identify several factors to consider that include operating costs, regulatory environment, 
domestic markets, engineering talent, political stability, currency fluctuations, facility costs, infrastructure, and language skills.

Due to the plurality of criteria, multi-criteria decision analysis methods have been largely used to solve location selection problems. Gupta, Mehlawat, \& Grover (2016) combined VIKOR and trapezoidal intuitionistic fuzzy numbers for selecting a plant location. Decision Making Trial and Evaluation Laboratory (DEMATEL), the Analytic Network Process (ANP) and Multi-Attributive Border Approximation area Comparison (MABAC) have been combined to selecting wind farm locations (Gigović, Pamučar, Božanić, \& Ljubojević, 2017). A 2-tuple hybrid ordered weighted averaging (THOWA) has been used for the location selection of city logistics centres (Rao, Goh, Zhao, \& Zheng, 2015).

Fuzzy AHP-TOPSIS has been adopted for the selection of thermal power plant location (Choudhary \& Shankar, 2012). AHP and ELECTRE have been combined for selecting the location of a dry port location (Ka, 2011). Fuzzy AHP-TOPSIS has been applied for location selection for landfill of industrial wastes. PROMETHEE, TOPSIS and MAUT have been used to select the location of a new casino (Ishizaka, Nemery, \& Lidouh, 2013). AHP was used for selecting a plant location (Gothwal \& Saha, 2015). As it can be seen, there are a high number of studies on location selection. However, only few have tackled outsourcing location selection. Liu, Berger, Zeng, \& Gerstenfeld (2008) have used AHP to select an outsourcing location. Lin, Wang, \& Qin (2007) combine AHP and PROMETHEE.

Mihalache \& Mihalache (2015) underline that the current research largely considers offshore location decisions from a static perspective. However, they indicate the need to incorporate changing conditions in the foreign locations, including wage levels and skills. This raises the question of whether firms are able to sense and respond to these changing conditions. In order to answer this question, our study uses a FCM coupled with AHP.

\subsection{Capabilities in a resilient Supply Chain}

SC disruptions are increasingly more frequent. These may lead to an excessive rise in costs, stock-out, delays, inability to serve clients demand, in addition to loss of market position of 
the firm (Blackhurst, Craighead, Elkins, \& Handfield, 2005; Norrman \& Jansson, 2004; Yosef Sheffi, 2005; Tang, 2006). These negative effects would be reduced with the presence of resilience capabilities among network members (Craighead, Blackhurst, Rungtusanatham, \& Handfiel, 2007). Hence, in the last decades, it had raised among practitioners and academics a growing interest in building more resilient SC and preserving it.

Initially, Christopher \& Peck (2004) formulated principles for creating resilient SC based upon a SC (re)engineering, risk management culture, agility and collaboration between entities. With this in mind, Tang (2006) describes robust strategies addressed at improving enterprises capabilities to preserve their operations when an unexpected disruption happens. The dynamic nature of these capabilities strengthens firms and support its readiness, response and faster recovery to the normal activities or even to reach a better standing.

Earlier studies pointed out the capabilities required to make SC more resilient (Chopra \& Sodhi, 2004; Pettit, Croxton, \& Fiksel, 2013; Ponomarov \& Holcomb, 2009; Tukamuhabwa, Stevenson, Busby, \& Zorzini, 2015). These are mainly flexibility, redundancy, collaboration, visibility and multiple sourcing (Zailani, Subaramaniam, Iranmanesh, \& Shaharudin, 2015). Other works provide comprehensive frameworks on how these capabilities support the disaster management process (Ponomarov \& Holcomb, 2009; Scholten, Scott, \& Fynes, 2014). Wieland \& Wallenburg (2013) focus their attention on how relational capabilities (communication, co-operation and integration) may impact SC resilience. Soni, Jain, \& Kumar (2014) go one step further by modelling interdependences between them.

The review of the literature shows that the capabilities required to achieve a resilient SC have been extensively studied. However, these may be affected by other SC management decisions. This is the case for offshore outsourcing process (Bailey \& De Propris, 2014; Juttner, Peck, \& Christopher, 2003). A recent study describes synergies between driving factors for re-shoring decisions and resilience SC (Soroka, Naim, Purvis, \& Hopkins, 2015). From the offshoring process perspective, we provide a hybrid FCM-AHP model for forecasting impacts of alternative locations on SC resilience. Next section explains this new 
method in detail.

\section{Methodology}

\subsection{Theoretical foundations of FCM}

FCM were firstly introduced by Kosko (1986). This artificial intelligence technique is an extension of Cognitive Maps (CM) that integrates characteristics of fuzzy sets and neural networks. Axerold (1976) provided the idea of CM for supporting decision-making. In addition to the important points (called nodes), he added causal connections between them (called edges). CM have been thereafter useful in problem solving when many decisional variables are causally interrelated (Jetter \& Kok, 2014) because it can help decision-makers to highlight and analyse hidden relationships that contribute most to reaching relevant and significant solutions.

$\mathrm{CM}$ are signed digraphs where only the direction of the change between two nodes is modeled. A positive edge (noted with a positive sign + ) indicates that the causal node casually increases or decreases the effect node in its same direction. A negative edge means that the causal node increases or decreases the effect node in its opposite direction.

In contrast to $\mathrm{CM}$, FCM with fuzzy weights has the ability to deal with uncertain and imprecise data. This was introduced to model the intensity of the change when event occurs only to some degree (Kosko, 1986). More specifically, a FCM model is a graph-based knowledge representation (Dickerson \& Kosko, 1993) which models a static or dynamic system using causal dependencies between a set of $n$ nodes $V=\left(v_{1}, v_{2}, \ldots, v_{n}\right)$. The intensity of causal connection between pair of nodes $\left\langle v_{i}, v_{j}\right\rangle$ is evaluated by assigning fuzzy weights $\left(w_{i \rightarrow j} \in[-1,1]\right)$, where $v_{i}$ is the pre-synaptic (causal) node and $v_{j}$ is the postsynaptic (effect) node. The entire relationships can be represented in an adjacency matrix $(W)$ with their sign and intensity (1). Three possible types of causal relationships among concepts can be entered in $W$ :

- $w_{i \rightarrow j}>0$ denotes positive causality, which implies that a change in $v_{i}$ provokes a 
modification in $v_{j}$ in the same direction.

- $w_{i \rightarrow j}<0$ denotes negative causality, which implies that a change in $v_{i}$ provokes a modification in $v_{j}$ in the opposite direction.

- $w_{i \rightarrow j}=0$ denotes there is no relationship between $v_{i}$ and $v_{j}$.

$$
W=\left(\begin{array}{cccc}
\ldots & \ldots & \ldots & w_{1 \rightarrow n} \\
\ldots & \ldots & \ldots & \ldots \\
\ldots & \ldots & w_{i \rightarrow j} & \ldots \\
\ldots & \ldots & \ldots & \ldots \\
\ldots & \ldots & \ldots & w_{n \rightarrow n}
\end{array}\right)
$$

\subsection{Building an augmented FCM-AHP model}

Different methods can be used to build FCMs. These are normally constructed through a multi-step process, where experts in the domain develop their mental models. In doing so, we propose to combine augmented FCM with AHP.

FCM has already been previously hybridized with diverse techniques for supporting decision-making methods. The driving forces for developing hybrid approaches lies in: A. Avoiding the weaknesses of individual techniques and integrating their strengths; or B. Getting multiplicity of application tasks when a single technique cannot deal with different sub-problems of the given task (Li, Davies, Edwards, Kinman, \& Duan, 2002). Table 1 provides a comparison list of hybrid approaches based on FCM and their reason.

Concerning the driving force B, FCM allows to calculate local and/or global weights to be used in TOPSIS, AHP and ANP to assess alternatives (Baykasoğlu \& Gölcük, 2015; Nachazel, 2015; Yu \& Tzeng, 2006). FCM thus overcomes the problem of interdependence among criteria, as well as the problem of hard questions derived from pairwise comparison. On the other side, AHP allows to determine the initial state vector simulated in the FCM inference process by considering multiple criteria (Biloslavo \& Dolinsek, 2010). Primitive Cognitive Network Process (PCNP) measures the initial values of experts to be further process in FCM (Zhou \& Yuen, 2014). However, the question of tranforming linguistic 
evaluations of feedback between FCM variables into quantative evaluations has not been yet tackled. 
Table 2. List of hybrid approaches based on FCM

\begin{tabular}{|c|c|c|c|c|}
\hline Article & Objectif & Combined techniques & $\begin{array}{l}\text { Driving } \\
\text { forces }\end{array}$ & Explanation \\
\hline (Yu \& Tzeng, 2006) & Numerical examples & ANP and FCM & A & FCM estimates global weight vector of ANP \\
\hline $\begin{array}{c}\text { (Biloslavo \& } \\
\text { Dolinsek, 2010) }\end{array}$ & $\begin{array}{l}\text { Impact of organizational and } \\
\text { technological changes on } \\
\text { climate-related issues }\end{array}$ & $\begin{array}{l}\text { Delphi, AHP and } \\
\text { FCM }\end{array}$ & A & $\begin{array}{l}\text { Delphi tehcinques identify factors, AHP computes } \\
\text { the initial state vector then simulated in the FCM } \\
\text { inference process }\end{array}$ \\
\hline (Shiau \& Liu, 2013) & $\begin{array}{l}\text { Evaluate transport sustainability } \\
\text { strategies }\end{array}$ & $\mathrm{AHP}$ and $\mathrm{FCM}$ & B & $\begin{array}{l}\text { AHP ranks key sustainable indicators. The } 10 \text { first } \\
\text { are used in the FCM to build causal-relationships } \\
\text { between them }\end{array}$ \\
\hline $\begin{array}{l}\text { (Asadi, Soltani, } \\
\text { Gasevic, Hatala, \& } \\
\text { Bagheri, 2014) }\end{array}$ & $\begin{array}{l}\text { Determine automated feature } \\
\text { model configuration }\end{array}$ & $\mathrm{AHP}, \mathrm{FCM}$ and $\mathrm{HTN}$ & B & $\begin{array}{l}\text { AHP calculates local weights; meanwhile FCM } \\
\text { estimates global weights. HTN finds the optimal } \\
\text { feature model configuration. }\end{array}$ \\
\hline $\begin{array}{l}\text { (Zhou \& Yuen, } \\
\text { 2014) }\end{array}$ & $\begin{array}{l}\text { Measure the factors on box } \\
\text { office sales }\end{array}$ & PCNP and FCM & A & $\begin{array}{l}\text { PCNP quantifies the weights of factors to } \\
\text { construct a concept in FCM. FCM simulates the } \\
\text { influences on each others. }\end{array}$ \\
\hline $\begin{array}{l}\text { (Ahmadi, Yeh, } \\
\text { Papageorgiou, \& } \\
\text { Martin, 2015) }\end{array}$ & $\begin{array}{l}\text { Managing readiness relevant } \\
\text { activities in implementing an } \\
\text { ERP system }\end{array}$ & $\begin{array}{l}\text { FAHP, FCM and } \\
\text { DEMATEL }\end{array}$ & B & $\begin{array}{l}\text { FAHP computes the readiness contribution } \\
\text { weight of activities. FCM determines how these } \\
\text { activities interact on each other. The multiplication } \\
\text { of both FAHP and FCM inference's results } \\
\text { determines the overall ERP readiness. DEMATEL } \\
\text { analyses the results of the ERP readiness } \\
\text { assessment by using static FCM model. }\end{array}$ \\
\hline $\begin{array}{l}\text { (Azadeh, Zarrin, } \\
\text { Abdollahi, Noury, \& } \\
\text { Farahmand, 2015) }\end{array}$ & $\begin{array}{l}\text { Evaluating and optimizing the } \\
\text { leanness degree of } \\
\text { organizations }\end{array}$ & $\begin{array}{c}\text { FDEA, FCM, } \\
\text { DEMATEL and AHP }\end{array}$ & B & $\begin{array}{l}\text { FCM and FDEA separately quantify firms } \\
\text { leanness and rank them. DEMATEL evaluates } \\
\text { impact degree of the leanness factors on each } \\
\text { other, and subsequently AHP and DEA ranks } \\
\text { them. }\end{array}$ \\
\hline $\begin{array}{l}\text { (Baykasoğlu \& } \\
\text { Gölcük, 2015) }\end{array}$ & $\begin{array}{l}\text { Prioritize strategies for } \\
\text { transforming higher education } \\
\text { systems. }\end{array}$ & $\begin{array}{l}\text { Fuzzy TOPSIS and } \\
\text { FCM }\end{array}$ & A & $\begin{array}{l}\text { FCM calculates the attribute weights To be used } \\
\text { in TOPSIS to rank alternatives }\end{array}$ \\
\hline (Nachazel, 2015) & Decision-making in artificial life & $\mathrm{AHP}$ and $\mathrm{FCM}$ & A & $\begin{array}{l}\text { FCM estimates the weights of criteria used to } \\
\text { determine which activity should individual choose } \\
\text { with AHP }\end{array}$ \\
\hline $\begin{array}{l}\text { (Kang, Zhang, \& } \\
\text { Bai, 2016) }\end{array}$ & $\begin{array}{l}\text { Evaluation of the oil-spill } \\
\text { emergency response capability }\end{array}$ & $\mathrm{AHP}$ and $\mathrm{FCM}$ & B & $\begin{array}{l}\text { FCM and AHP determine the weights in first and } \\
\text { second levels of the distribution model, } \\
\text { respectively. }\end{array}$ \\
\hline
\end{tabular}


The defuzzification is often carried out by using the centroid method, the max aggregation method or the mamdani inference mechanism (Mago, Mehta, Woolrych, \& Papageorgiou, 2012). In our paper, AHP generates quantitative evaluations from the linguistic evaluation of the experts (Ishizaka \& Nguyen, 2013, Meesariganda \& Ishizaka, 2017). Furthermore, this method incorporates a consistency measure, which strengthens the robustness of the final FCM model. Hence, we propose a new combination of FCM and AHP. The main steps in the process are as follows:

Step 1. Experts identify key variables (nodes) that describe a targeted system (or real problem).

Step 2. Experts identify causal connections between nodes $\left(w_{i \rightarrow j}\right)$. This requires to define the type of relationship (positive or negative) between $v_{i}$ and $v_{j}$, as well as the intensity. It can be expressed in form of IF-THEN rules, where the sender or influencing node follows a binary code (ON or OFF) and the receiver or influenced node increases (+) or decreases (-) by a level evaluated using linguistic terms. Thus, one graphical FCM model is obtained for each expert $\left(E_{i}\right)$. This also is formally called adjacency matrix $\left(W^{E_{i}}\right)$.

Step 3. All fuzzy evaluations are mapped into a range $[-1,1]$, where negative number represents negative causalities. Hence, linguistic evaluations need to be translated into this quantitative range. This is a difficult task that has been overlooked in the literature. In this paper, we propose to use AHP (Ishizaka \& Labib, 2011; Saaty, 1980) for this transformation. The $n$ linguistic terms are pairwise compared in a square matrix A (2) on a 1-9 evaluation scale, where 1 indicates the equal importance and 9 the extreme importance.

$$
\mathbf{A}=\left[\begin{array}{cccc}
1 & a_{12} & & a_{1 n} \\
a_{21} & \ldots & a_{i j} & \ldots \\
\ldots & a_{j i}=1 / a_{i j} & \ldots & \ldots \\
a_{n 1} & \ldots & \ldots & 1
\end{array}\right]
$$

where $a_{i j}$ is the comparison between the linguistic term I and $j$

The matrix is reciprocal $a_{i j}=1 / a_{i i}$ with the diagonal being equal at the unity because the 
linguistic term is compared with itself. Therefore, only the upper part of the matrix is required from the experts (Ishizaka, 2012). If a matrix is sufficiently consistent, weights are calculated as shown in formula (3) (Ishizaka \& Lusti, 2006):

$\mathrm{AW}=\lambda_{\max } \mathrm{W}$

where $A$ is the comparison matrix,

$\lambda_{\max }$ is the principal eigenvalue

W is the vector of the weights.

As $A$ has a redundancy of information, the consistency of the entered judgments by the experts can be tested with the consistency ratio $(\mathrm{CR})$ :

$\mathrm{CR}=\mathrm{Cl} / \mathrm{RI}$

where $\mathrm{Cl}=\left(\lambda_{\max }-n\right) /(n-1)$ is the consistency index

$n$ is the dimension of the comparison matrix

$\lambda_{\max }$ is the principal eigenvalue

$\mathrm{RI}$ is the ratio index.

The ratio index $(R I)$ is the average of the consistency index of numerous randomly filled matrices. Saaty (1977) considers that a consistency ratio exceeding $10 \%$ may indicate a set of judgments too inconsistent to be reliable and therefore recommends to revise the evaluations.

Step 4. As experts' models are normally quite different, it may be necessary to use other methodologies to reach a consensus between them such as the Delphi method (Jetter \& Kok, 2014; Nalchigar, Nasserzadeh, \& Akhgar, 2011) or the augmented method(Ahmadi et al., 2015; Lopez \& Salmeron, 2014).

In the augmented FCM method, the adjacency matrices provided by all experts are added to obtain the final diagraph-based FCM model (Dickerson \& Kosko, 1993). This approach does not need that experts change their former opinions to obtain a consensus as in the Delphi methodology (Salmeron, 2009). In addition, experts' models are not constrained by a closed list of concepts in such a way to ensure that the final FCM represents all the insights. For these reasons, we propose to use the augmented approach to build the FCM. 
The ultimate the aim of the augmented FCM method is to generate the augmented adjacency matrix $\left(W^{A U G}\right)$ from the outputs achieved in the previous steps. For this purpose, the $W^{E_{i}}$ of each expert are added. When more than one participant assign non-zero $w_{i \rightarrow j}$ value, then $w_{i \rightarrow j}^{A u g}=\sum_{k=1}^{n} w_{i \rightarrow j}^{P_{k}} / n$ where $k$ is the identifier of each participant and $n$ is the number of experts. FCM model also incorporates connections indicated by one expert without the need of any additional transformation. Finally, the augmented graph-based model is drawn in line with the adjacency matrix obtained $\left(W^{A U G}\right)$.

\subsection{FCM inferences}

FCM is not only used to represent a causal reasoning of the phenomenon. It allows also predicting future implications through dynamic simulations of scenarios. For this purpose, FCM incorporates the concept of neurons in the sense that it can be "on" $(+1)$ or "off" $(-1)$ but also states in-between which are fuzzy states. When a node changes its state, it affects all other connected nodes. If the threshold level of the effect node is reached, it will also change state and by consequence may also change further nodes within the network. Already activated nodes may be even altered again due to a feedback loop. By consequence, the activation spreads in a non-linear manner until the system reaches its stability or a chaotic behaviour.

The inference process begins by assigning an input value $[0,1]$ to each FCM node, which corresponds to the initial state vector:

$V_{S_{i}}^{0}=\left(\begin{array}{lllll}v_{1}^{0} & v_{2}^{0} & \ldots & v_{n-1}^{0} & v_{n}^{0}\end{array}\right)$

where $v_{n}^{0}$ points out the value of the node at the instant 0 .

During the simulation process, inputs are computed through a finite number of interactions in chain according to the following formula (Stylios \& Groumpos, 2004)

$v_{i}^{t+1}=f\left(v_{i}^{t}+\sum_{i \neq j}^{n} v_{j}^{t} \cdot \omega_{j \rightarrow i}\right)$ 
where $v_{i}^{t+1}$ is the value of node $v_{i}$ at the instant $t+1, \omega_{i \rightarrow j}$ is the fuzzy weight expressing the intensity of causal relationship between nodes $v_{j}$ and $v_{i}$, and $f(x)$ is the transformation function. Researches should assess the existing transformation functions in order to select the one that is most suitable to the requirements of the study. The most commonly applied transformation functions are (Nápoles, Papageorgiou, Bello, \& Vanhoof, 2016; Tsadiras, 2008) :

The binary (7) is a discrete function where nodes can be either activated or not. This is capable of representing an increase of a node or a stable behaviour. However, it is not capable of representing a decrease of a node. In this case, chaotic attractor will not be reached in the inference process. Therefore, the binary transformation function should be applied in highly qualitative problems in which only increases and/or stability of nodes are modelled.

$$
f(x)= \begin{cases}1, & \text { if } x<0 \\ 0, & \text { if } x \geq 0\end{cases}
$$

The trivalent (8) is another discrete function which can represent an increase, decrease or stable behaviour of a node. It will also not produce a chaotic attractor. This should be thus applied in qualitative problem in where changes in any direction or stability are possible but the degree of change is irrelevant.

$$
f(x)= \begin{cases}0 & \text { if } x<0 \\ 1 & \text { if } x=0 \\ -1 & \text { if } x>0\end{cases}
$$

Both the sigmoid unipolar function (9) and the hyperbolic tangent function (10) are continuous transformation functions which can represent any degree of change. Hence, these can be used in qualitative and quantitative problems where the degree of change is relevant. According to (Feyzioglu, Buyukozkan, \& Ersoy, 2007), the hyperbolic tangent function is more suitable when fuzzy weights fall within the range $[-1,1]$.

$$
f(x)=\frac{1}{1+e^{-\lambda \cdot x}}
$$




$$
f(x)=\tanh (x)=\frac{e^{\lambda \cdot x}-e^{-\lambda \cdot x}}{e^{\lambda \cdot x}+e^{-\lambda \cdot x}}
$$

The continuous transformation functions use lambda $(\lambda)$ as a constant for the function slope. Although $\lambda=5$ has shown to get a good degree of normalization with the sigmoid function (Bueno \& Salmeron, 2009), it might tend to approximate outputs to extreme values , i.e. to one or zero, with the hyperbolic tangent function. On the contrary, for smaller values of $\lambda$, the hyperbolic function approximates a linear function. Earlier studies (Mago et al., 2012; Miao \& Liu, 2000) researched the best $\lambda$ and suggested $\lambda=1$.

A new value is calculated with (6) for each node at each time step. FCM inference finishes when the limit vector is reached. This happens when either $V^{t}=V^{t+1}$ or $V^{t+1}-$ $V^{t} \leq \varepsilon$; where $\varepsilon$ is a residua (Espinosa-Paredes, Nuñez-Carrera, Laureano-Cruces, Vázquez-Rodríguez, \& Espinosa-Martinez, 2008). The inference process can also result in a limit cycle. This implies that the vector state continues changing around several fixed states. When continuous transformation function is used [(9) or (10)], a chaotic behaviour is possible (Papageorgiou, 2011). This happens when the inference process finds different outputs for each time step, and therefore, the FCM does not reach stability. In this study, dynamic simulations of scenarios are used to foresee the impact of outsourcing off-shored location decisions on SC resilience. 


\section{Case study}

This section describes a real study of the augmented FCM-AHP method for supporting outsourcing offshore location decision-making considering SC resilience. Unlike empirical studies which pursue generalized findings, case studies have proved to be an excellent vehicle to examine real-life situations in the SCM (Seuring, 2008). In this study, we have been tasked to measure the resilience capacity as regards to the effects of outsourcing location by applying a single and explanatory case study (Yin, 2013).

A single case study research strategy has been sometimes criticized due to questionable generalizability of the results. However, this provide convincing findings especially when the real case selected to provide deep insights that alternative cases may not reveal (Siggelkow, 2007). Our chosen setting is of particular value since it assesses a global SC of spirit drinks with geographically remote locations worldwide. This SC is also characterized by high complexity, where only one SC entity, the focal producer, has more than 30 production facilities worldwide and multiple tiers of both suppliers and customers. In the past, that focal producer made several outsourcing and offshoring decisions. This firm has also implemented practices to improve its resilience capacity.

\subsection{A FCM model for supporting offshore outsourcing location decision-making} With the purpose of building the augmented FCM model in mind, we followed the process step-by-step described in Section 3.2. Two participants (experts) took part in the study. They currently occupy the business analyst position and the supply chain manager position in the firm. Through personal interviews of the experts by the authors of this paper, we constructed their diagraph. Our role was to extract their cognitive mapping. This task was quite easy as they worked since a long time on outsourcing and resilience strategies. The identified nodes are given in the Table 2 and Table 3. 
Table 3. Criteria considered in the offshore decisions

\begin{tabular}{cc}
\hline ID & Criterion \\
\hline Off1 & Quality of the final product \\
Off2 & Transport infrastructure \\
Off3 & Government regulation \\
Off4 & Cultural distance \\
Off5 & Delivery time \\
Off6 & Political risks \\
Off7 & Facility security \\
Off8 & Management cost \\
Off9 & Tax rates \\
Off10 & Transport cost \\
Off11 & Monitoring cost \\
Off12 & Technological infrastructure \\
Off13 & Exchange rates \\
Off14 & Labour cost \\
Off15 & Technical and language skills of employees \\
Off16 & Origin denomination regulatory compliance \\
\hline
\end{tabular}

Table 4: Capabilities detected in resilient SC

\begin{tabular}{cc}
\hline ID & Capability \\
\hline Res1 & Flexibility \\
Res2 & Visibility \\
Res3 & Anticipation \\
Res4 & Recovery \\
Res5 & Security \\
Res6 & Adaptability \\
Res7 & Financial strength \\
Res8 & Market position \\
Res9 & Collaboration \\
\hline
\end{tabular}

In the second step, they identified the sign, direction and intensity of causal connections between nodes (arcs). In order to define the intensity, we established six linguistic terms $\{$ None, Very Weak, Weak, Moderate, Strong, Very Strong\}. Experts used them to reflect the influence or strength of the causality $\left(w_{i \rightarrow j}\right)$ between pair of nodes $\left\langle v_{i}, v_{j}\right\rangle$.

In the third step, experts carried out a pairwise comparison between linguistic terms using 9 point scale proposed in (Saaty, 1977). Appendix A includes the questionnaire. From the pairwise comparisons, quantitative intensities are obtained with AHP (3). Table 4 shows the derived intensities. The consistency ratio remained below 0.1 for all comparisons matrices. All the experts have the same weights, and therefore the aggregate intensities is simply given by an average of each intensities. We thus reached an adjacency matrix provided by experts $\left(W^{E_{i}}\right)$ which consist of real numbers in the range $[-1,1]$. 
Table 5. Linguistics variables and their associated quantitative intensities.

\begin{tabular}{ccccc}
\hline Code & Fuzzy weights & $\begin{array}{c}\text { Intensities } \\
\text { (Participant 1) }\end{array}$ & $\begin{array}{c}\text { Intensities } \\
\text { (Participant 2) }\end{array}$ & $\begin{array}{c}\text { Intensities } \\
\text { (Global) }\end{array}$ \\
\hline $\mathrm{N}$ & None & 0 & 0 & 0 \\
VW & Very Weak & 0.032 & 0.042 & 0.037 \\
$\mathrm{~W}$ & Weak & 0.058 & 0.075 & 0.066 \\
$\mathrm{M}$ & Moderate & 0.113 & 0.141 & 0.127 \\
$\mathrm{~S}$ & Strong & 0.229 & 0.266 & 0.248 \\
VS & Very strong & 0.568 & 0.477 & 0.522 \\
\hline Inconsistency ratio & 0.07 & 0.007 & 0.03 \\
\hline
\end{tabular}

Finally, we applied step 4 to compute the final adjacency matrix $\left(W^{A u g}\right)$. This is given in Table 6. In addition, we drew a graph-based model in line with $W^{A u g}$. Figure 1 shows the complete FCM, which will be used to forecast the impacts of outsourcing offshore location decisions on SC resilience. Please note that neither of the two experts detected interactions between Off4 and the rest of nodes. Hence, it was not represented in the final FCM model. The graphical representation of the augmented FCM shows the following results:

- The FCM model includes causal connections between outsourcing offshore location criteria (nodes). Managers should pay special attention at the trigger nodes. These are transport infrastructure (Off2), political risks (Off6), tax rates (Off9), technological infrastructure (Off12) and exchange rates (Off13). Their impacts can generate a cascading effect on the rest of the criteria, and therefore their consequences in SC resilience are hard to predict. The dynamic behavior of the FCM may shed light on this matter.

- Outsourcing offshore location decisions may improve or harm the SC resilience. From Figure 1, we can observe that the criteria with the highest number of causal connection are transport cost (Off10) and technological infrastructure (Off12). They impact directly on 4 and 5 capabilities respectively. However, their effects are on an opposite direction. While Off10 exerts a negative effect, Off12 improves SC resilience. Therefore if a company aims to a higher resilience, the selected location should have a high-quality technological infrastructure, and generate low transport costs.

- The capabilities receiving the highest number of causal connections are Res1 
(Flexibility) and Res4 (Recovery). As they are both positively and negatively affected by offshoring criteria, the static analysis of the FCM do not provide enough evidence about improvement or harm.

- Furthermore, the indirect connections and hidden patters among nodes should be taken into account to foresee the impact of outsourcing offshore location decision on SC resilience. This issue can be clarified by analyzing the dynamic behavior of the FCM.

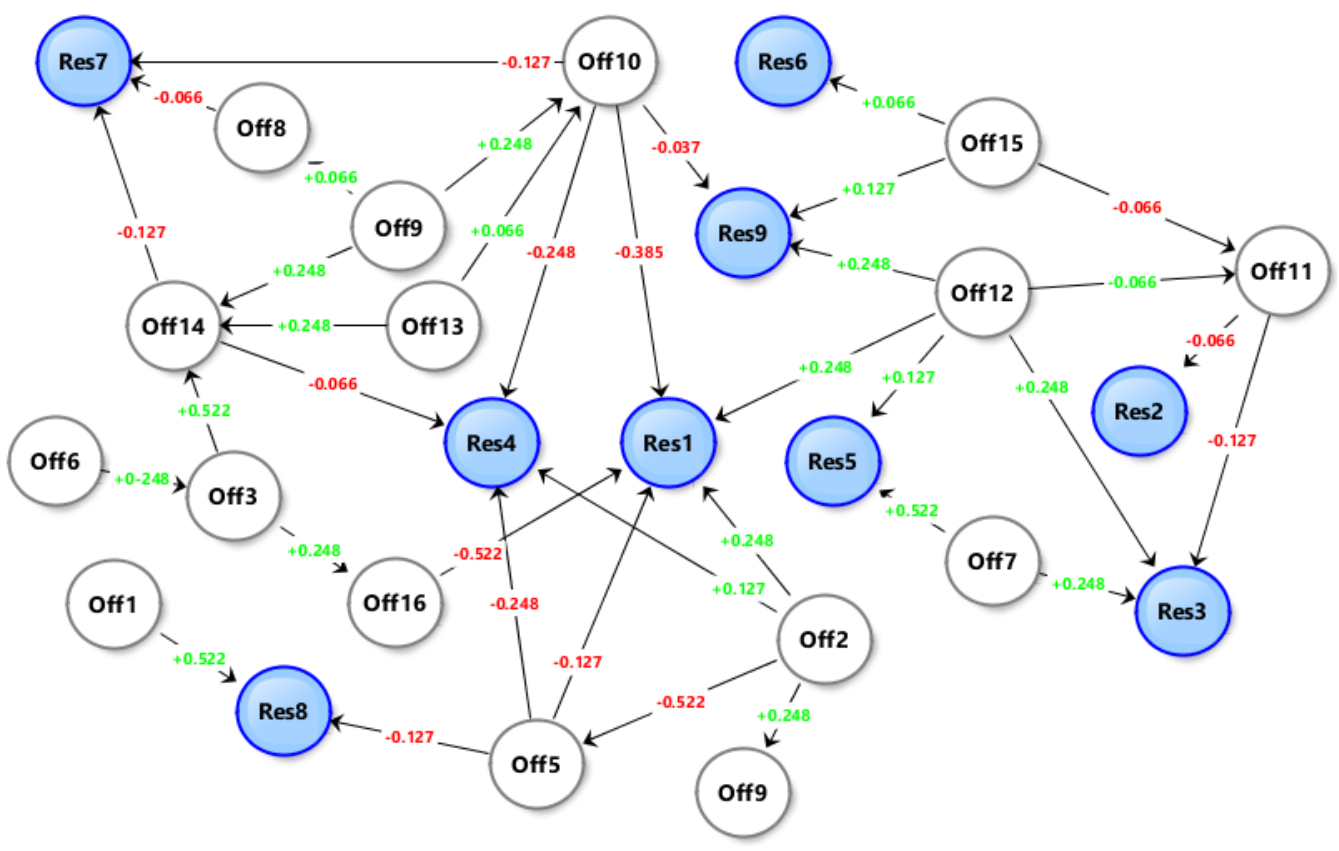

Figure 1. FCM for supporting offshore outsourcing location decision-making 
Table 6. Adjacency matrix

\begin{tabular}{|c|c|c|c|c|c|c|c|c|c|c|c|c|c|c|c|c|c|c|c|c|c|c|c|c|c|}
\hline ID & off 1 & off2 & off3 & off 4 & off5 & off 6 & off7 & off8 & off9 & off 10 & off11 & off 12 & off 13 & off 14 & off 15 & off16 & Res1 & Res2 & Res3 & Res4 & Res5 & Res6 & Res7 & Res8 & Res9 \\
\hline off1 & 0 & 0 & 0 & 0 & 0 & 0 & 0 & 0 & 0 & 0 & 0 & 0 & \begin{tabular}{l|} 
\\
\end{tabular} & 0 & 0 & 0 & 0 & 0 & 0 & 0 & 0 & 0 & 0 & 0,522 & 0 \\
\hline off2 & 0 & 0 & 0 & 0 & $-0,522$ & 0 & 0 & 0 & 0,248 & 0 & 0 & 0 & 0 & 0 & 0 & 0 & 0,248 & 0 & 0 & 0,127 & 0 & 0 & 0 & 0 & 0 \\
\hline off3 & 0 & 0 & 0 & 0 & 0 & 0 & 0 & 0 & 0 & 0 & 0 & 0 & 0 & 0,522 & 0 & 0,25 & 0 & 0 & 0 & 0 & 0 & 0 & 0 & 0 & 0 \\
\hline off4 & 0 & 0 & 0 & 0 & 0 & 0 & 0 & 0 & 0 & 0 & 0 & 0 & 0 & 0 & 0 & 0 & 0 & 0 & 0 & 0 & 0 & 0 & 0 & 0 & 0 \\
\hline off5 & 0 & 0 & 0 & 0 & 0 & 0 & 0 & 0 & 0 & 0 & 0 & 0 & 0 & 0 & 0 & 0 & $-0,127$ & 0 & 0 & $-0,248$ & 0 & 0 & 0 & $-0,127$ & 0 \\
\hline off6 & 0 & 0 & 0,248 & 0 & 0 & 0 & 0 & 0 & 0 & 0 & 0 & 0 & 0 & 0 & 0 & 0 & 0 & 0 & 0 & 0 & 0 & 0 & 0 & 0 & 0 \\
\hline off7 & 0 & 0 & 0 & 0 & 0 & 0 & 0 & 0 & 0 & 0 & 0 & 0 & 0 & 0 & 0 & 0 & 0 & 0 & 0,248 & 0 & 0,522 & 0 & 0 & 0 & 0 \\
\hline off8 & 0 & 0 & 0 & 0 & 0 & 0 & 0 & 0 & 0 & 0 & 0 & 0 & 0 & 0 & 0 & 0 & 0 & 0 & 0 & 0 & 0 & 0 & $-0,066$ & 0 & 0 \\
\hline off9 & 0 & 0 & 0 & 0 & 0 & 0 & 0 & 0,066 & 0 & 0,248 & 0 & 0 & 0 & 0,248 & 0 & 0 & 0 & 0 & 0 & 0 & 0 & 0 & 0 & 0 & 0 \\
\hline off 10 & 0 & 0 & 0 & 0 & 0 & 0 & 0 & 0 & 0 & 0 & 0 & 0 & 0 & 0 & 0 & 0 & $-0,385$ & 0 & 0 & $-0,248$ & 0 & 0 & $-0,127$ & 0 & $-0,037$ \\
\hline off11 & 0 & 0 & 0 & 0 & 0 & 0 & 0 & 0 & 0 & 0 & 0 & 0 & 0 & 0 & 0 & 0 & 0 & $-0,066$ & $-0,127$ & 0 & 0 & 0 & 0 & 0 & 0 \\
\hline off12 & 0 & 0 & 0 & 0 & 0 & 0 & 0 & 0 & 0 & 0 & $-0,066$ & 0 & 0 & 0 & 0 & 0 & 0,248 & 0,248 & 0,248 & 0 & 0,127 & 0 & 0 & 0 & 0,248 \\
\hline off 13 & 0 & 0 & 0 & 0 & 0 & 0 & 0 & 0 & 0 & 0,066 & 0 & 0 & 0 & 0,248 & 0 & 0 & 0 & 0 & 0 & 0 & 0 & 0 & 0 & 0 & 0 \\
\hline off14 & 0 & 0 & 0 & 0 & 0 & 0 & 0 & 0 & 0 & 0 & 0 & 0 & 0 & 0 & 0 & 0 & 0 & 0 & 0 & $-0,066$ & 0 & 0 & $-0,127$ & 0 & 0 \\
\hline off 15 & 0 & 0 & 0 & 0 & 0 & 0 & 0 & 0 & 0 & 0 & $-0,066$ & 0 & 0 & 0 & 0 & 0 & 0 & 0 & 0 & 0 & 0 & 0,07 & 0 & 0 & 0,127 \\
\hline off 16 & 0 & 0 & 0 & 0 & 0 & 0 & 0 & 0 & 0 & 0 & 0 & 0 & 0 & 0 & 0 & 0 & $-0,522$ & 0 & 0 & 0 & 0 & 0 & 0 & 0 & 0 \\
\hline Res 1 & 0 & 0 & 0 & 0 & 0 & 0 & 0 & 0 & 0 & 0 & 0 & 0 & 0 & 0 & 0 & 0 & 0 & 0 & 0 & 0 & 0 & 0 & 0 & 0 & 0 \\
\hline Res2 & 0 & 0 & 0 & 0 & 0 & 0 & 0 & 0 & 0 & 0 & 0 & 0 & 0 & 0 & 0 & 0 & 0 & 0 & 0 & 0 & 0 & 0 & 0 & 0 & 0 \\
\hline Res3 & 0 & 0 & 0 & 0 & 0 & 0 & 0 & 0 & 0 & 0 & 0 & 0 & 0 & 0 & 0 & 0 & 0 & 0 & 0 & 0 & 0 & 0 & 0 & 0 & 0 \\
\hline Res4 & 0 & 0 & 0 & 0 & 0 & 0 & 0 & 0 & 0 & 0 & 0 & 0 & 0 & 0 & 0 & 0 & 0 & 0 & 0 & 0 & 0 & 0 & 0 & 0 & 0 \\
\hline Res5 & 0 & 0 & 0 & 0 & 0 & 0 & 0 & 0 & 0 & 0 & 0 & 0 & 0 & 0 & 0 & 0 & 0 & 0 & 0 & 0 & 0 & 0 & 0 & 0 & 0 \\
\hline Res 6 & 0 & 0 & 0 & 0 & 0 & 0 & 0 & 0 & 0 & 0 & 0 & 0 & 0 & 0 & 0 & 0 & 0 & 0 & 0 & 0 & 0 & 0 & 0 & 0 & 0 \\
\hline Res7 & 0 & 0 & 0 & 0 & 0 & 0 & 0 & 0 & 0 & 0 & 0 & 0 & 0 & 0 & 0 & 0 & 0 & 0 & 0 & 0 & 0 & 0 & 0 & 0 & 0 \\
\hline Res8 & 0 & 0 & 0 & 0 & 0 & 0 & 0 & 0 & 0 & 0 & 0 & 0 & 0 & 0 & 0 & 0 & 0 & 0 & 0 & 0 & 0 & 0 & 0 & 0 & 0 \\
\hline Res9 & 0 & 0 & 0 & 0 & 0 & 0 & 0 & 0 & 0 & 0 & 0 & 0 & 0 & 0 & 0 & 0 & 0 & 0 & 0 & 0 & 0 & 0 & 0 & 0 & 0 \\
\hline
\end{tabular}




\subsection{Simulating alternative location scenarios}

The static analysis of FCM allows only identifying the direct relationships between nodes. We can also evaluate the dynamic behaviour of the model over time by applying an inference process as described in Section 3.3. These results will help managers to foresee the effect of offshoring location decision-making in the resilience of their SC.

The inference process begins by defining the scenarios to be simulated. With this goal in mind, the same experts were consulted. They explain us that the firm can offshore the entire production process of one of their products in either of three different partner facilities. We identify them as location 1, location 2 and location 3 . We carried out a moderated group discussion in which experts assessed them. In this way, they assigned a score belonging to the range $[0,1]$ to each outsourcing offshore location criterion included in the final FCM model (Figure1). Each score represents how much a location fulfils a criterion, where 1 means a full fulfilment and 0 no fulfilment. In order to simplify this task, a five-point scale was developed (Table 7). Table 8 shows the location scores given as regards to each criterion.

Table 7. Five-point scale

\begin{tabular}{cc}
\hline Score & Expression \\
\hline 0 & Standard/Very low \\
0.25 & Fair/Low \\
0.5 & Good/High \\
0.75 & Very good/ Very high \\
1 & Excellent/Extremelly high \\
\hline
\end{tabular}


Table 8. Location scenarios

\begin{tabular}{|c|c|c|c|c|c|c|}
\hline & \multicolumn{2}{|r|}{ Location 1} & \multicolumn{2}{|r|}{ Location 2} & \multicolumn{2}{|r|}{ Location 3} \\
\hline Node & Score & Description & Score & Description & Score & Description \\
\hline Off1 & 0 & - & 0 & - & 0 & - \\
\hline Off2 & 1 & $\begin{array}{l}\text { Excellent transport } \\
\text { infrastructure }\end{array}$ & 0 & - & 0 & - \\
\hline Off3 & 0 & - & 0 & - & 0 & - \\
\hline Off4 & 0 & - & 0 & - & 0 & - \\
\hline Off5 & 0 & - & 0 & - & 0.75 & Very high delivery time \\
\hline Off6 & 0 & - & 1 & $\begin{array}{l}\text { Extremely high } \\
\text { political risks }\end{array}$ & 0.5 & High political risk \\
\hline Off7 & 1 & $\begin{array}{l}\text { Excellent facility } \\
\text { security }\end{array}$ & 0.25 & Fair facility security & 0.5 & Good facility security \\
\hline Off8 & 0.75 & $\begin{array}{l}\text { Very high } \\
\text { management cost }\end{array}$ & 0 & - & 0 & - \\
\hline Off9 & 1 & $\begin{array}{l}\text { Extremely high tax } \\
\text { rates }\end{array}$ & 0 & 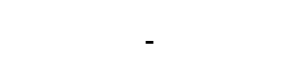 & 0 & - \\
\hline Off 10 & 0 & $x_{1}$ & 0.5 & $\begin{array}{l}\text { High transportation } \\
\text { costs }\end{array}$ & 1 & $\begin{array}{l}\text { Extremely high } \\
\text { transportation cost }\end{array}$ \\
\hline Off11 & 0 & - & 0.5 & $\begin{array}{l}\text { High monitoring } \\
\text { costs }\end{array}$ & 0.5 & High monitoring cost \\
\hline Off12 & 0.5 & $\begin{array}{l}\text { Good technological } \\
\text { infrastructure }\end{array}$ & 0 & - & 0 & - \\
\hline Off13 & 1 & $\begin{array}{l}\text { Extremely high } \\
\text { exchange rates }\end{array}$ & 0 & - & 0 & - \\
\hline Off14 & 1 & $\begin{array}{l}\text { Extremely high } \\
\text { labour cost }\end{array}$ & 0.25 & Low labour cost & 0 & - \\
\hline Off15 & 1 & $\begin{array}{l}\text { Employees with } \\
\text { excellent technical } \\
\text { and language skills }\end{array}$ & 0 & - & 0.5 & $\begin{array}{l}\text { Employees with good } \\
\text { technical and language } \\
\text { skills }\end{array}$ \\
\hline Off16 & 0 & - & 0 & - & 0 & - \\
\hline
\end{tabular}

Subsequently, we define the three scenarios, one for each location, at the instant 0 , with (5). Each scenario is simulated by computing (5) and $W^{A u g}$ through (6). Given that fuzzy weights are within the range $[-1,1]$, we applied the hyperbolic tangent function (10) (Feyzioglu et al., 2007; Stylios \& Groumpos, 2000) with $\lambda=1$. Section 3.3 gives a more detailed explanation about the selection of the transformation function. Scenarios 1,2 and 3 reached stability after 121,123 and 185 time steps respectively, with $\varepsilon \leq 0.0001$. Table 9 presents the results obtained in the inference process. 
Table 9. Results of the simulation of Location 1, 2 and 3

\begin{tabular}{ccccccc}
\hline & \multicolumn{2}{c}{ Location 1 } & \multicolumn{2}{c}{ Location 2 } & \multicolumn{2}{c}{ Location 3 } \\
\hline Nodes & Input & Output & Input & Output & Input & Output \\
\hline Off1 & 0 & 0.000 & 0 & 0.000 & 0 & 0.000 \\
Off2 & 1 & 0.154 & 0 & 0.000 & 0 & 0.000 \\
Off3 & 0 & 0.000 & 0 & 0.468 & 0 & 0.436 \\
Off5 & 0 & -0.580 & 0 & 0.000 & 0.75 & 0.125 \\
Off6 & 0 & 0.000 & 1 & 0.153 & 0.5 & 0.123 \\
Off7 & 1 & 0.154 & 0.25 & 0.132 & 0.5 & 0.123 \\
Off8 & 0.75 & 0.436 & 0 & 0.000 & 0 & 0.000 \\
Off9 & 1 & 0.469 & 0 & 0.000 & 0 & 0.000 \\
Off10 & 0 & 0.653 & 0.5 & 0.148 & 1 & 0.126 \\
Off11 & 0 & -0.387 & 0.5 & 0.148 & 0.5 & -0.291 \\
Off12 & 0.5 & 0.149 & 0 & 0.000 & 0 & 0.000 \\
Off13 & 1 & 0.154 & 0 & 0.000 & 0 & 0.000 \\
Off14 & 1 & 0.688 & 0.25 & 0.766 & 0 & 0.754 \\
Off15 & 1 & 0.154 & 0 & 0.000 & 0.5 & 0.123 \\
Off16 & 0 & 0.000 & 0 & 0.638 & 0 & 0.626 \\
\hline Res1 & 0 & -0.613 & 0 & -0.844 & 0 & -0.844 \\
Res2 & 0 & 0.539 & 0 & -0.311 & 0 & 0.376 \\
Res3 & 0 & 0.651 & 0 & 0.341 & 0 & 0.549 \\
Res4 & 0 & -0.477 & 0 & -0.591 & 0 & -0.632 \\
Res5 & 0 & 0.614 & 0 & 0.554 & 0 & 0.543 \\
Res6 & 0 & 0.316 & 0 & 0.000 & 0 & 0.291 \\
Res7 & 0 & -0.731 & 0 & -0.638 & 0 & -0.631 \\
Res8 & 0 & 0.563 & 0 & 0.000 & 0 & -0.358 \\
Res9 & 0 & 0.450 & 0 & -0.258 & 0 & 0.319 \\
\hline
\end{tabular}

\subsubsection{Results of simulation of scenario 1}

The simulation of the scenario 1 shows how the outsourcing of the production process in location 1 may affect SC resilience of the firm studied. In order to a better understand about it, the appendix B shows a detailed analysis how this simulation may impact on other location criteria. Focusing our attention on resilience capabilities, Figure 2 shows the effects of this simulation over time. Capacities reach stability in the range of -0.731 to 0.651 . This scenario alters all resilience capabilities with both positive and negative influences. More specifically, the anticipation (Res3) reached the highest positive value $(0.651)$. This is due to the negative impact of the monitoring cost required (Off11) that is smaller than the positive influences of an excellence facility security (Off7) and a good technological infrastructure (Off12). The SC security (Res5) receives a very similar impact $(0.614)$ due to the positive effects of Off7 and Off12. In addition, market position (Res8) also obtains a positive slightly 
higher influence $(0.563)$, which might be caused by the decrease in delivery time (Off5). The other side of the coin is the financial strength. Outsourcing the production process in location 1 may highly damage the SC financial strength $(\operatorname{Res} 7=-0.731)$. The effect of extremely high taxes (Off9) and exchange rates (Off13) may trigger a cascade of effects on the transport cost (Off10) and the labour cost (Off14). All this taken together, the very high rise of management cost (Off8) explains the negative repercussion of location 1 on the financial strength. However, this does not mean that outsourcing offshore the production in location 1 generates economic loss, even if it requires very high economic efforts.

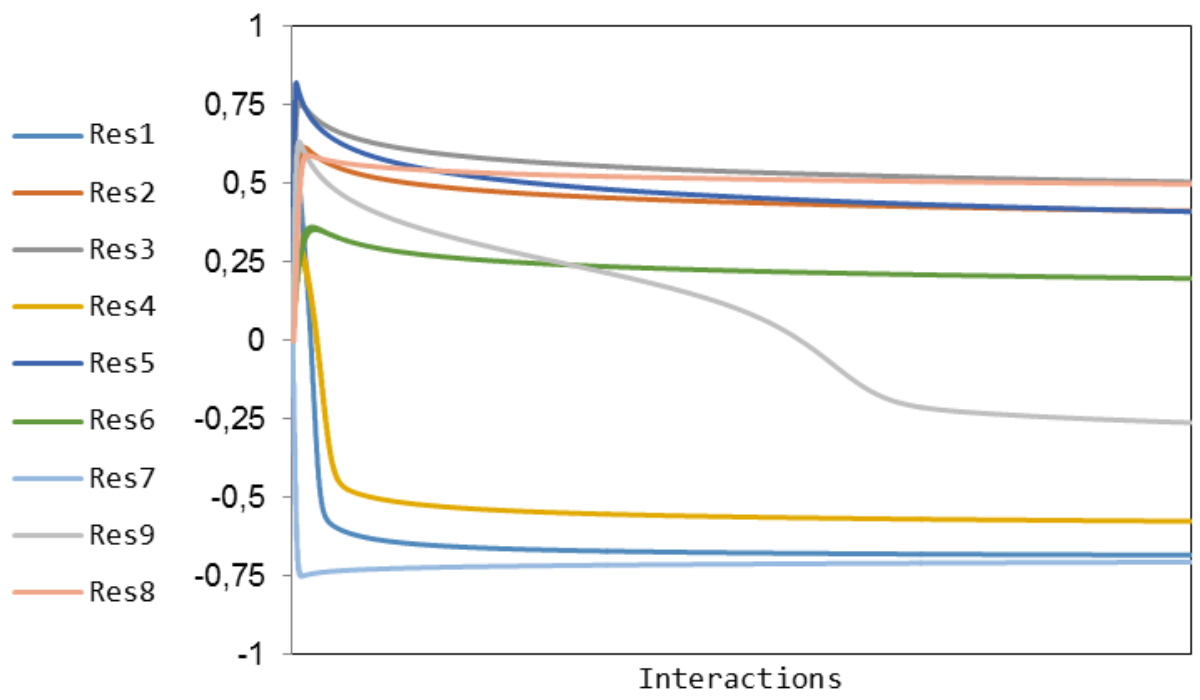

Figure 2. Results of simulating location 1 on resilience capabilities.

\subsubsection{Results of simulation of scenario 2}

The simulation of the scenario 2 displays how outsourcing the production process in location 2 may influence SC resilience. A more detailed about effects in no activated location criteria is presented in Appendix B.Figure 3 represents the impacts of that location on resilience capacities. The simulation of scenario 2 did not have any impact on the adaptability (Res6) and the market position (Res8). The other resilience capabilities reaches values in the range of -0.844 to 0.554 . Results reveal that location 2 leads to moderate improvement in security (0.554) and a slightly moderate improvement in anticipation (Res3 $=0.341)$. The other effects on the resilience capabilities were negatives. The flexibility (Res1) received the highest negative impact $(-0.844)$. The high transportation cost (0ff10) and the ripple effect 
caused by the high political risks (Off6) would explain this high loss of SC flexibility. Moreover, as in scenario 1 , we can observe a negative impact on financial strength in a lower magnitude $(-0.638)$. This happens because the lower taxes, exchange rates and labour costs offset the increase in transportation costs.

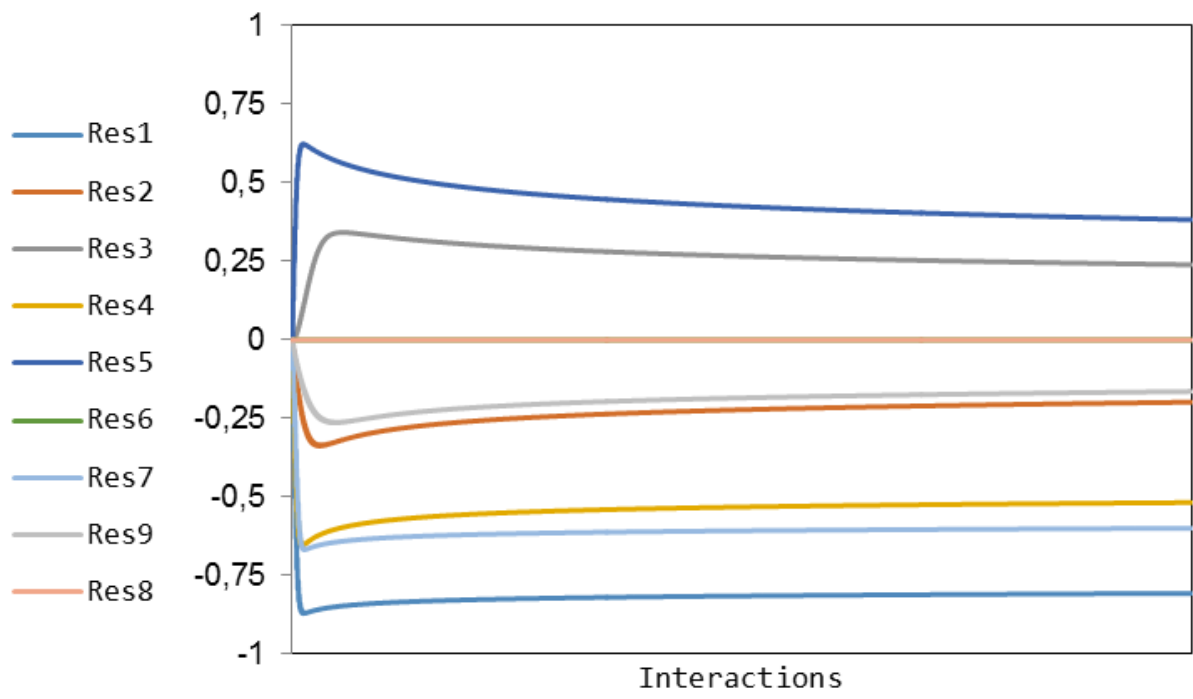

Figure 3. Results of simulating location 2 on resilience capabilities.

\subsubsection{Results of simulation of scenario 3}

The simulation of the scenario 3 indicates how outsourcing the production process in location 3 may affect SC resilience of the firm studied. Appendix B presents impacts on no activated location criteria.On the resilience capacities side, figure 4 shows that all nodes were altered. Their values are within the interval [-0.844, 0.549]. As in scenario 1, the anticipation (Res3) was the most strongly affected, although its intensity was moderate in scenario 3 (0.549). This can be explained by the indirect and positive effect of employees with good technical and language skills (Off15) from location 3 . The simulation of scenario 3 also exerted a moderate positive influence in Res5 (0.543). This might be the consequence of a good facility security from location 3 (Off7). As in scenario 2 , the flexibility suffered the highest negative impact (-0.844). Moreover, financial strength (Res7) was again negative and slightly more affected (-0.631). A very different result is reached by the market position capability (Res8). Results point out that when the production process is offshored in location 3 , Res8 is negative and slightly moderately damaged (-0.358). This is due to in the very high delivery time (Off5) of location 3. 


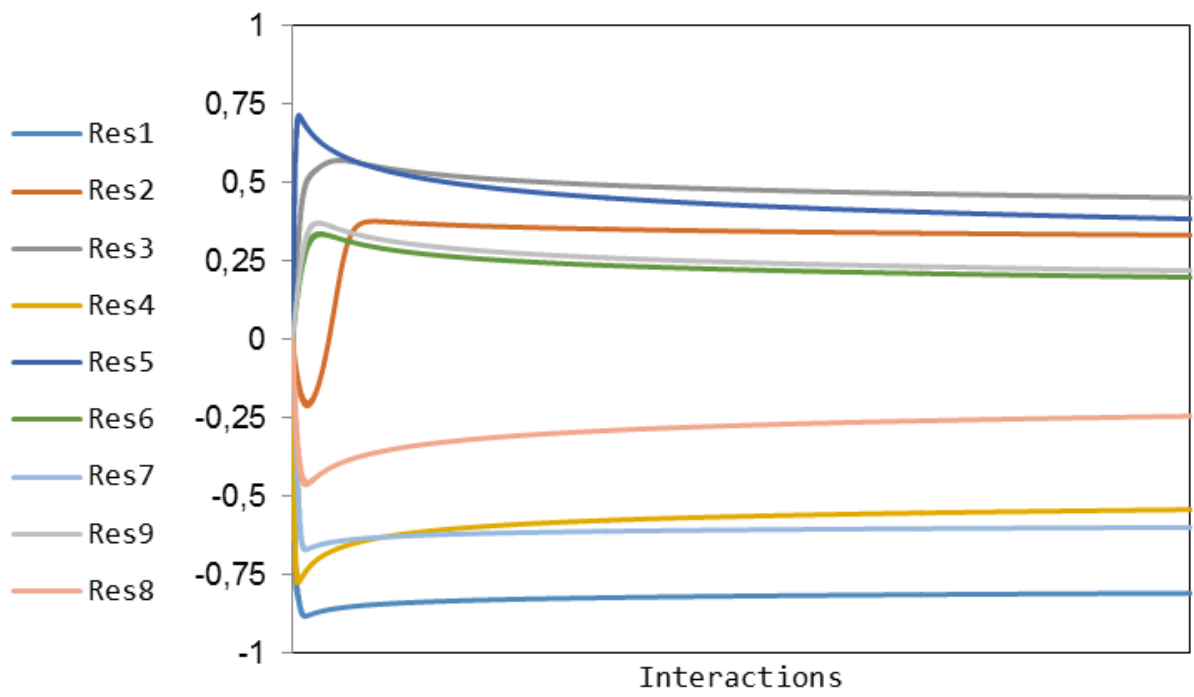

Figure 4. Results of simulating location 3 on resilience capabilities.

\subsubsection{Sensitivity analysis of location impacts on SC resilience capacities}

The comparison between the impacts of three location on the SC resilience highlights relevant issues. Figure 5 depicts how the scenarios influence each resilience capability. Depending on the scenario simulated, these are improved, preserved or damaged.

The three locations may impact negatively on Flexibility. It is interesting to note that location 2 and 3 have exactly the same influence $(-0.844)$, while location 1 generates a lower effect $(-0.613)$. This is due to the positive effect of Transport infrastructure and Technological infrastructure only activated in location 1 . However, it is not enough to compensate the high cost caused by Tax rates and Exchange rates in location 1. Hence, if managers seek to preserve or improve the Flexibility, the location should provide a good Tax rates and Exchange rates, as well as reduced transport cost and delivery time.

Regarding the Visibility, location 1 has a positive moderate influence with (0.539), whereas location 3 causes a slightly lower impact (0.376). Location 2 presents a negative effect $(-0.311)$. The positive impacts implied by location 1 and 3 are found despite the unfavourable and direct effect of the Monitoring cost. This is probably due to the activation of the Technological infrastructure and the Technical and language skills of employees, which are at a good and excellent levels in scenario 1, respectively. Hence, if managers aim to improve or preserve a high Visibility, they should choose location 1. Location 3 ranks at the 
second position because it provides a good level of Technical and language skills of employees and a standard Technological infrastructure, as well as a high Monitoring cost. If we just consider the Visibility, location 2 should be discarded, since the effect of their high Monitoring cost is not compensated by the standards of the Technological Infrastructure and the Exchange rates.

The three locations may have a positive impact on the Anticipation. Location 1 is again ranked at the first position with a slightly high improvement (0.651). In fact, scenario 1 presents an excellent Facility security, whereas scenario 3 and 2 show a good and fair Facility security respectively. Hence, location 3 reaches the second position and location 2 the last one.

The three locations may damage the Recovery. Scenario 1 affects moderately negatively the Recovery (-0.477). Although location 1 relies on an excellent Transport infrastructure, their extremely high labour cost makes the Recovery difficult. Scenario 2 exerts a negative high influence on the Recovery (-0.591). This is due to a high Transport cost and low Labour cost. The highest damage on the Recovery is observed in Scenario 3. The effect of a very high Delivery time and extremely high Transport cost explains its negative high influence (0.632). Therefore, if the aim of the firm is to improve or preserve the Recovery, it should rule out all the three locations. With that goal in mind, managers should select a location with low level of Delivery time, Transport cost and Exchange rates and a good Transport infrastructure.

Concerning the Security, all the three locations may have a positive impact. The Facility security and the Technological infrastructure can directly cause improvements on the Security. From this standpoint, location 1 is also ranked at the first position with a slightly high improvement (0.614). This is due to an excellent Facility security and good Technological infrastructure. Location 2 and 3 generates almost identical impact, respectively 0.554 and 0.543 . Hence, location 2 reaches the second position and location 3 the last one. 
Adaptability may be only improved with a slightly moderate intensity by the scenario 1 (0.316) and 3 (0.291). Scenario 2 does not impact the Adaptability. This is explained by the direct effect of Technical and language skills of employees. Locations 1 and 3 have respectively an excellent and good Technical and language skills of employees. Therefore, they are ranked at the first two positions.

The three locations may cause a loss on the Financial strength. If we see Figure 1, the Financial strength is directly affected by the location criteria related to offshore location costs. Hence, an economic effort is required by the location decision. Accordingly, managers should firstly choose location $3(-0.631)$ followed by location $2(-0.638)$ and location 1 ($0.731)$.

Regarding the Market position, the three locations may lead to widely disparate effects. Location 1 may cause a moderate improvement in the Market position (0.563), whereas location 2 does not have any influence. The positive effect of location 1 is explained by the indirect effect of good Technological infrastructure on the Market position. However, location 3 presents a slightly negative effect $(-0.358)$. This is due to its very high Delivery time. Therefore, if managers pursue to improve the Market position, they should choose location 1.

The collaboration has a positive moderate improvement $(0.45)$ in location 1 , whereas location 3 causes slightly lower moderate impact (0.319). Location 2 has a negative effect (0.258). This is explained by the direct negative action of a high Transport cost. The finding of location 3 are positive despite the unfavourable direct effect of the Transport cost. This may be compensated by the positive effect of the good Technical and language skills of employees in scenario 3. At the contrary, location 1 presents a good Technological infrastructure and excellent Technical and language skills of employees. Therefore, if managers pursue to improve or preserve the Collaboration, they should choose locations 1 and 3 in the first and second place, respectively.

By adding all effects caused by each location, we thus obtain their global impact. The findings highlight that when the firm offshore the production process in location 1, SC 
resilience may be improved. At the contrary, location 2 and 3 may damage it. Hence, from a resilient SC point of view, the firm studied should chose location 1.

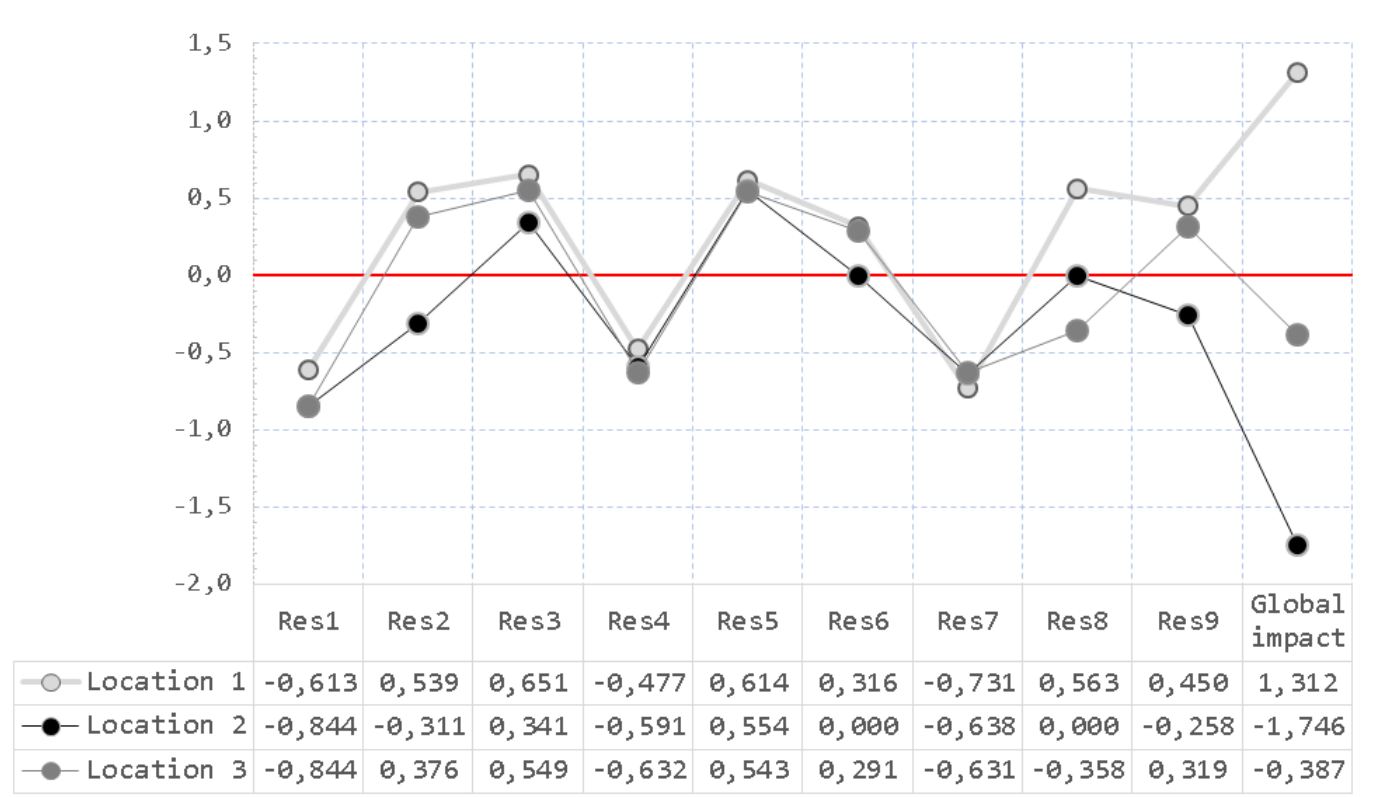

Figure 5. Results of sensitivity analysis of location effects in resilience capacity.

\section{Conclusions}

Outsourcing is a technique that has been used since a long time. However, today its usage has sharply increased and its associated risks too. In this paper, we have developed a new framework to assess the impact of outsourcing practices on the SC resilience capabilities. It is based on the hybridation of FCM and Analytic Hierarchy Process. The new hybrid method is capable of quantifying the uncertainty in causal connections in a precise way. The main methodological contribution is the precise transformation of linguistic evaluations into quantitative ones with AHP. It is to note that constructing the FCM is not an easy task. In our case study, this exercise has not been difficult because the experts worked a long time on the outsourcing problematic and resilience capabilities.

The proposed method can support practitioners while evaluating alternative outsourcing locations according to their impacts on the SC resilience. Experts perceived the main advantage of the proposed method in the ability to predict effects due to indirect implications, which are otherwise very difficult to predict, especially for large models. In fact, in our case, 
one location would improve resilient capabilities and two locations would rather damaged it. Such location behavior could not been predicted without our simulation.

The simulations also highlight that offshore outsourcing processes may damage Flexibility, Financial strengths, and Recovery capacity of SC. These damages are explained by the negative influences of the Delivery time, Tax rate, Exchange rate, Transport cost and Labor costs. Hence, if practitioners pursue to preserve those capabilities, they should choose the location, which significantly reduces the above-mentioned criteria. On the contrary, the results reveal that offshore outsourcing processes may reinforce Security and Anticipation capabilities. This happens when the location has a good Technological infrastructure and the Facility security. The above-mentioned criteria should thus have hight weights.

It would be very relevant for practitioners to know when the FCM predictions will happen (in the short, half or long term). However, the inference mechanism of FCM lacks a measure of time. To overcome this weakness, new hybrid methods would be developed in future studies.

For academics, this paper provides a groundwork for further studies because it is the first time that a research shows how offshore outsourcing location decision-making can improve, preserve or damage SC resilience. Looking to the future, empirical works would validate the influences detected. In addition, the developed hybrid method is generic, flexible and easily adaptable. Therefore, it could be applied easily to other sectors to represent messy problems with causalities and predict future outcomes. 


\section{Appendix A. Extract of the questionnaire}

Circle one number per row below using the scale:

$1=$ Equal $3=$ Moderate $5=$ Strong $7=$ Very strong $9=$ Extreme

$2,4,6,8$ are intermediate values

Compare the relative performance of one linguistic term with all other linguistic terms to determine the strength of relationship between FCM nodes.

\begin{tabular}{|c|ccccccccccccccccc|c|}
\hline None & 9 & 8 & 7 & 6 & 5 & 4 & 3 & 2 & 1 & 2 & 3 & 4 & 5 & 6 & 7 & 8 & 9 & Very Weak \\
\hline None & 9 & 8 & 7 & 6 & 5 & 4 & 3 & 2 & 1 & 2 & 3 & 4 & 5 & 6 & 7 & 8 & 9 & Weak \\
\hline None & 9 & 8 & 7 & 6 & 5 & 4 & 3 & 2 & 1 & 2 & 3 & 4 & 5 & 6 & 7 & 8 & 9 & Moderate \\
\hline None & 9 & 8 & 7 & 6 & 5 & 4 & 3 & 2 & 1 & 2 & 3 & 4 & 5 & 6 & 7 & 8 & 9 & Strong \\
\hline None & 9 & 8 & 7 & 6 & 5 & 4 & 3 & 2 & 1 & 2 & 3 & 4 & 5 & 6 & 7 & 8 & 9 & Very strong \\
\hline Very Weak & 9 & 8 & 7 & 6 & 5 & 4 & 3 & 2 & 1 & 2 & 3 & 4 & 5 & 6 & 7 & 8 & 9 & Weak \\
\hline Very Weak & 9 & 8 & 7 & 6 & 5 & 4 & 3 & 2 & 1 & 2 & 3 & 4 & 5 & 6 & 7 & 8 & 9 & Moderate \\
\hline Very Weak & 9 & 8 & 7 & 6 & 5 & 4 & 3 & 2 & 1 & 2 & 3 & 4 & 5 & 6 & 7 & 8 & 9 & Strong \\
\hline Very Weak & 9 & 8 & 7 & 6 & 5 & 4 & 3 & 2 & 1 & 2 & 3 & 4 & 5 & 6 & 7 & 8 & 9 & Very strong \\
\hline Weak & 9 & 8 & 7 & 6 & 5 & 4 & 3 & 2 & 1 & 2 & 3 & 4 & 5 & 6 & 7 & 8 & 9 & Moderate \\
\hline Weak & 9 & 8 & 7 & 6 & 5 & 4 & 3 & 2 & 1 & 2 & 3 & 4 & 5 & 6 & 7 & 8 & 9 & Strong \\
\hline Weak & 9 & 8 & 7 & 6 & 5 & 4 & 3 & 2 & 1 & 2 & 3 & 4 & 5 & 6 & 7 & 8 & 9 & Very strong \\
\hline Moderate & 9 & 8 & 7 & 6 & 5 & 4 & 3 & 2 & 1 & 2 & 3 & 4 & 5 & 6 & 7 & 8 & 9 & Strong \\
\hline Moderate & 9 & 8 & 7 & 6 & 5 & 4 & 3 & 2 & 1 & 2 & 3 & 4 & 5 & 6 & 7 & 8 & 9 & Very strong \\
\hline Strong & 9 & 8 & 7 & 6 & 5 & 4 & 3 & 2 & 1 & 2 & 3 & 4 & 5 & 6 & 7 & 8 & 9 & Very strong \\
\hline
\end{tabular}




\section{Appendix B. Detailed analysis of the simulation effects in no location criteria activated}

\begin{tabular}{|c|c|c|c|c|c|c|}
\hline \multirow[b]{2}{*}{ Node } & \multicolumn{2}{|r|}{ Location 1} & \multicolumn{2}{|r|}{ Location 2} & \multicolumn{2}{|r|}{ Location 3} \\
\hline & Output & Explanation & Output & Description & Output & Description \\
\hline Off1 & 0.000 & NA & 0.000 & NA & 0.000 & NA \\
\hline Off2 & 0.154 & $\mathrm{CA}$ & 0.000 & NA & 0.000 & NA \\
\hline Off3 & 0.000 & NA & 0.468 & $\begin{array}{l}\text { The extremely high } \\
\text { political risks might } \\
\text { cause its moderate } \\
\text { rise. }\end{array}$ & 0.436 & $\begin{array}{l}\text { The extremely high } \\
\text { political risks might cause } \\
\text { its moderate rise. }\end{array}$ \\
\hline Off5 & -0.580 & $\begin{array}{l}\text { Moderately reduced, } \\
\text { since location } 1 \text { is } \\
\text { near to the main } \\
\text { market of the } \\
\text { product. Indeed, this } \\
\text { does not regress the } \\
\text { units produced to the } \\
\text { client firm, but go } \\
\text { straight to their } \\
\text { channels of } \\
\text { distribution. }\end{array}$ & 0.000 & NA & 0.125 & $\mathrm{CA}$ \\
\hline Off6 & 0.000 & NA & 0.153 & $\mathrm{CA}$ & 0.123 & $\mathrm{CA}$ \\
\hline Off7 & 0.154 & $\mathrm{CA}$ & 0.132 & $\mathrm{CA}$ & 0.123 & $\mathrm{CA}$ \\
\hline Off8 & 0.436 & $\mathrm{CA}$ & 0.000 & NA & 0.000 & NA \\
\hline Off9 & 0.469 & $\mathrm{CA}$ & 0.000 & NA & 0.000 & NA \\
\hline Off10 & 0.653 & $\begin{array}{l}\text { Slightly higher by the } \\
\text { extremely high taxes } \\
\text { and exchange rates } \\
\text { existing in location } 1 .\end{array}$ & 0.148 & $\mathrm{CA}$ & 0.126 & $\mathrm{CA}$ \\
\hline Off11 & -0.387 & $\begin{array}{l}\text { These are driven } \\
\text { down although with } \\
\text { a moderate intensity. } \\
\text { The technological } \\
\text { infrastructure and } \\
\text { high-qualified } \\
\text { employees in } \\
\text { location } 1 \text { make this } \\
\text { task easier. }\end{array}$ & 0.148 & $\mathrm{CA}$ & -0.291 & $\mathrm{CA}$ \\
\hline Off12 & 0.149 & $\mathrm{CA}$ & 0.000 & NA & 0.000 & NA \\
\hline Off13 & 0.154 & $\mathrm{CA}$ & 0.000 & NA & 0.000 & NA \\
\hline Off14 & 0.688 & $\mathrm{CA}$ & 0.766 & $\mathrm{CA}$ & 0.754 & $\begin{array}{l}\text { High increase due to the } \\
\text { indirect effect of high } \\
\text { political risks. }\end{array}$ \\
\hline Off15 & 0.154 & $\mathrm{CA}$ & 0.000 & NA & 0.123 & $\mathrm{CA}$ \\
\hline Off16 & 0.000 & NA & 0.638 & $\begin{array}{l}\text { Slightly high increase } \\
\text { due to the indirect } \\
\text { effect of extremely } \\
\text { high political risks. }\end{array}$ & 0.626 & $\begin{array}{c}\text { Slightly high increase due } \\
\text { to the indirect effect of } \\
\text { extremely high political } \\
\text { risks. }\end{array}$ \\
\hline
\end{tabular}

Note: NA: Not Altered

CA: Criterion activated 


\section{REFERENCES}

Ahmadi, S., Yeh, C. H., Papageorgiou, E. I., \& Martin, R. (2015). An FCM-FAHP approach for managing readiness-relevant activities for ERP implementation. Computers and Industrial Engineering, 88, 501-517. http://doi.org/10.1016/j.cie.2015.07.006

Asadi, M., Soltani, S., Gasevic, D., Hatala, M., \& Bagheri, E. (2014). Toward automated feature model configuration with optimizing non-functional requirements. Information and Software Technology, 56(9), 1144-1165. http://doi.org/10.1016/j.infsof.2014.03.005

Axelrod, R. (1976). Structure of Decision :The Cognitive Maps of Political Elites. Princeton, New Jersey: Princeton University Press.

Azadeh, A., Zarrin, M., Abdollahi, M., Noury, S., \& Farahmand, S. (2015). Leanness assessment and optimization by fuzzy cognitive map and multivariate analysis. Expert Systems with Applications, 42(15-16), 6050-6064. http://doi.org/10.1016/j.eswa.2015.04.007

Bailey, D., \& De Propris, L. (2014). Manufacturing reshoring and its limits: The UK automotive case. Cambridge Journal of Regions, Economy and Society, 7(3), 379-395. http://doi.org/10.1093/cjres/rsu019

Baykasoğlu, A., \& Gölcük, İ. (2015). Development of a novel multiple-attribute decision making model via fuzzy cognitive maps and hierarchical fuzzy TOPSIS. Information Sciences, 301, 75-98. http://doi.org/10.1016/j.ins.2014.12.048

Biloslavo, R., \& Dolinsek, S. (2010). Scenario planning for climate strategies development by integrating group Delphi, AHP and dynamic fuzzy cognitive maps. Foresight, 12(2), 38-48. http://doi.org/10.1109/PICMET.2008.4599720

Blackhurst, J., Craighead, C. W., Elkins, D., \& Handfield, R. B. (2005). An empirically derived agenda of critical research issues for managing supply-chain disruptions. International Journal of Production Research, 43(19), 4067-4081. http://doi.org/10.1080/00207540500151549

Blackhurst, J., Dunn, K. S., \& Craighead, C. W. (2011). An empirically derived framework of global supply resiliency. Journal of Business Logistics, 32(4), 374391. http://doi.org/10.1111/j.0000-0000.2011.01032.x

Bueno, S., \& Salmeron, J. L. (2009). Benchmarking main activation functions in fuzzy cognitive maps. Expert Systems with Applications, 36(3), 5221-5229. http://doi.org/10.1016/j.eswa.2008.06.072

Chopra, S., \& Sodhi, M. S. (2004). Managing risk to avoid supply-chain breakdown. MIT Sloan Management Review, 46(46109), 53-61. http://doi.org/10.1108/lJOPM-10-2012-0449

Choudhary, D., \& Shankar, R. (2012). An STEEP-fuzzy AHP-TOPSIS framework for evaluation and selection of thermal power plant location: A case study from 
India. Energy, 42(1), 510-521. http://doi.org/10.1016/j.energy.2012.03.010

Christopher, M., \& Peck, H. (2004). Building the resilient supply chain. International Journal of Logistics Management, 15(2), 1-14.

http://doi.org/10.1080/13675560600717763

Craighead, C. W., Blackhurst, J., Rungtusanatham, M. J., \& Handfiel, R. B. (2007). The Severity of Supply Chain Disruptions : Design Characteristics and Mitigation Capabilities. Decision Sciences, 38(1), 131-156.

Dickerson, J. A., \& Kosko, B. (1993). Virtual Worlds as Fuzzy Cognitive Maps. In IEEE Virtual Reality Annual International Symposium (pp. 471-477). Seatle, WA, USA: IEEE. http://doi.org/10.1109/VRAIS.1993.380742

Espinosa-Paredes, G., Nuñez-Carrera, A., Laureano-Cruces, A. L., VázquezRodríguez, A., \& Espinosa-Martinez, E. G. (2008). Emergency management for a nuclear power plant using fuzzy cognitive maps. Annals of Nuclear Energy, 35(12), 2387-2396. http://doi.org/10.1016/j.anucene.2008.07.007

Feyzioglu, O., Buyukozkan, G., \& Ersoy, M. S. (2007). Supply chain risk analysis with fuzzy cognitive maps. In IEEE International Conference on Industrial Engineering and Engineering Management (pp. 1447-1451). Singapore. http://doi.org/10.1109/IEEM.2007.4419432

Gigović, L., Pamučar, D., Božanić, D., \& Ljubojević, S. (2017). Application of the GIS-DANP-MABAC multi-criteria model for selecting the location of wind farms: A case study of Vojvodina, Serbia. Renewable Energy, 103, 501-521. http://doi.org/10.1016/j.renene.2016.11.057

Gothwal, S., \& Saha, R. (2015). Plant location selection of a manufacturing industry using analytic hierarchy process approach. International Journal of Services and Operations Management, 22(2), 235-255.

Gupta, P., Mehlawat, M. K., \& Grover, N. (2016). Intuitionistic fuzzy multi-attribute group decision-making with an application to plant location selection based on a new extended VIKOR method. Information Sciences, 370-371(1), 184-203. http://doi.org/10.1016/j.ins.2016.07.058

Ishizaka, A. (2012). Clusters and pivots for evaluating a large number of alternatives in AHP. Pesquisa Operacional, 32(1), 87-101.

Ishizaka, A., \& Labib, A. (2011). Review of the main developments in the analytic hierarchy process. Expert Systems with Applications, 38(11), 14336-14345. http://doi.org/10.1016/j.eswa.2011.04.143

Ishizaka, A., \& Lusti, M. (2006). How to derive priorities in AHP: A comparative study. Central European Journal of Operations Research, 14(4), 387-400. http://doi.org/10.1007/s10100-006-0012-9

Ishizaka, A., Nemery, P., \& Lidouh, K. (2013). Location selection for the construction of a casino in the Greater London region: A triple multi-criteria approach.

Tourism Management, 34, 211-220. 
http://doi.org/10.1016/j.tourman.2012.05.003

Ishizaka, A., \& Nguyen, N. H. (2013). Calibrated fuzzy AHP for current bank account selection. Expert Systems with Applications, 40(9), 3775-3783.

http://doi.org/10.1016/j.eswa.2012.12.089

Jetter, A. J., \& Kok, K. (2014). Fuzzy Cognitive Maps for futures studies-A methodological assessment of concepts and methods. Futures, 61, 45-57. http://doi.org/10.1016/j.futures.2014.05.002

Juttner, U., Peck, H., \& Christopher, M. (2003). Supply chain risk management: outlining an agenda for future research. International Journal of Logistics Research and Applications, 6(4), 197-210. http://doi.org/10.1080/13675560310001627016

Ka, B. (2011). Application of fuzzy AHP and ELECTRE to China dry port location selection. Asian Journal of Shipping and Logistics, 27(2), 331-354. http://doi.org/10.1016/S2092-5212(11)80015-5

Kang, J., Zhang, J., \& Bai, Y. (2016). Modeling and evaluation of the oil-spill emergency response capability based on linguistic variables. Marine Pollution Bulletin, 113(1-2), 293-301. http://doi.org/10.1016/j.marpolbul.2016.09.056

Kosko, B. (1986). Fuzzy Cognitive Maps. Int. Jornal of Man-Machine Studies, 1(April 1985), 65-75. http://doi.org/10.1016/S0020-7373(86)80040-2

Kosko, B. (1992). Neural Networks and Fuzzy Systems. Englewood Cliffs, NJ: Prentice-Hall.

Li, S., Davies, B., Edwards, J., Kinman, R., \& Duan, Y. (2002). Integrating group Delphi, fuzzy logic and expert systems for marketing strategy development: the hybridisation and its effectiveness. Marketing Intelligence \& Planning, 20(5), 273-284. http://doi.org/10.1108/02634500210441521

Lin, Z. K., Wang, J. J., \& Qin, Y. Y. (2007). A decision model for selecting an offshore outsourcing location: Using a multicriteria method. 2007 IEEE International Conference on Service Operations and Logistics, and Informatics, SOLI. http://doi.org/10.1109/SOLI.2007.4383936

Liu, L. B., Berger, P., Zeng, A., \& Gerstenfeld, A. (2008). Applying the analytic hierarchy process to the offshore outsourcing location decision. Supply Chain Management: An International Journal, 13(6), 435-449. http://doi.org/10.1108/13598540810905697

Lopez, C., \& Salmeron, J. L. (2014). Dynamic risks modelling in ERP maintenance projects with FCM. Information Sciences, 256, 25-45.

http://doi.org/10.1016/j.ins.2012.05.026

Mago, V. K., Mehta, R., Woolrych, R., \& Papageorgiou, E. I. (2012). Supporting meningitis diagnosis amongst infants and children through the use of fuzzy cognitive mapping. BMC Medical Informatics and Decision Making, 12(98), 112. http://doi.org/10.1186/1472-6947-12-98 
Meesariganda, B., Ishizaka, A. (2017). Mapping verbal AHP scale to numerical scale for cloud computing strategy selection, Applied Soft Computing, 53, 111-118. https://doi.org/10.1016/j.asoc.2016.12.040

Miao, Y., \& Liu, Z.-Q. (2000). On causal inference in fuzzy cognitive maps. IEEE Transactions on Fuzzy Systems, 8(1), 107-119. http://doi.org/10.1109/91.824780

Mihalache, M., \& Mihalache, O. R. (2015). A decisional framework of offshoring: Integrating insights from 25 years of research to provide direction for future*. Decision Sciences, O(0), n/a--n/a. http://doi.org/10.1111/deci.12206

Nachazel, T. (2015). Optimization of decision-making in artificial life model based on Fuzzy Cognitive Maps. In International Conference on Intelligent Environments (pp. 136-139). Prague, Czech Republic. http://doi.org/10.1109/IE.2015.28

Nalchigar, S., Nasserzadeh, S. M. R., \& Akhgar, B. (2011). Simulating strategic information systems planning process using fuzzy cognitive map. International Journal of Business Information Systems, 8(3), 286. http://doi.org/10.1504/IJBIS.2011.042410

Nápoles, G., Papageorgiou, E., Bello, R., \& Vanhoof, K. (2016). On the convergence of sigmoid Fuzzy Cognitive Maps. Information Sciences, 350, 154-171. http://doi.org/10.1016/j.ins.2016.02.040

Norrman, A., \& Jansson, U. (2004). Ericsson's proactive supply chain risk management approach after a serious sub-supplier accident. International Journal of Physical Distribution \& Logistics Management, 34(5), 434-456. http://doi.org/10.1108/S1479-3563(2012)000012B005

Papageorgiou, E. I. (2011). A new methodology for Decisions in Medical Informatics using fuzzy cognitive maps based on fuzzy rule-extraction techniques. Applied Soft Computing Journal, 11(1), 500-513. http://doi.org/10.1016/j.asoc.2009.12.010

Pettit, T. J., Croxton, K. L., \& Fiksel, J. (2013). Ensuring Supply Chain Resilience: Development and Implementation of an Assessment Tool. Journal of Business Logistics, 34(1), 46-76. http://doi.org/10.1111/jbl.12009

Pettit, T. J., Fiksel, J., \& Croxton, K. L. (2010). Ensuring Supply Chain Resilience: Development of a Conceptual Framework. Journal of Business Logistics, 31(1), 1-21. http://doi.org/10.1002/j.2158-1592.2010.tb00125.x

Ponomarov, S. Y., \& Holcomb, M. C. (2009). Understanding the concept of supply chain resilience. The International Journal of Logistics Management, 20(1), 124143. http://doi.org/10.1108/09574090910954873

Rao, C., Goh, M., Zhao, Y., \& Zheng, J. (2015). Location selection of city logistics centers under sustainability. Transportation Research Part D: Transport and Environment, 36, 29-44. http://doi.org/10.1016/j.trd.2015.02.008

Rice, J. B., \& Caniato, F. (2003). Building a secure and resilient supply network. 
Supply Chain Management Review, 7(5), 22-30.

http://doi.org/10.1080/13675560600717763

Saaty, T. L. (1977). A scaling method for priorities in hierarchical structures. Journal of Mathematical Psychology, 15(3), 234-281. http://doi.org/10.1016/00222496(77)90033-5

Saaty, T. L. (1980). The Analytic Hierarchy Process: Planning, Priority Setting, Resource Allocation (Decision Making Series). New York, NY: McGraw-Hill International Book Co. Retrieved from http://www.amazon.com/The-AnalyticHierarchy-Process-Allocation/dp/0070543712

Salmeron, J. L. (2009). Augmented fuzzy cognitive maps for modelling LMS critical success factors. Knowledge-Based Systems, 22(4), 275-278. http://doi.org/10.1016/j.knosys.2009.01.002

Scholten, K., Scott, P. S., \& Fynes, B. (2014). Mitigation processes - antecedents for building supply chain resilience. Supply Chain Management, 19(2), 211-228. http://doi.org/10.1108/SCM-06-2013-0191

Seuring, S. A. (2008). Assessing the rigor of case study research in supply chain management. Supply Chain Management: An International Journal, 13(2), 128137. http://doi.org/10.1108/13598540810860967

Sheffi, Y. (2005). The resilient enterprise : overcoming vulnerability for competitive advantage. Cambridge, Massashusetts: Cambridge, Mass. : MIT Pres.

Sheffi, Y., \& Rice Jr, J. B. (2005). A Supply Chain View of the Resilient Enterprise. MIT Sloan Management Review, 47(1), 41-48. Retrieved from http://search.ebscohost.com/login. aspx?direct=true\&db=buh\&AN=18837361\&sit $\mathrm{e}=$ ehost-live

Shiau, T. A., \& Liu, J. S. (2013). Developing an indicator system for local governments to evaluate transport sustainability strategies. Ecological Indicators, 34, 361-371. http://doi.org/10.1016/j.ecolind.2013.06.001

Siggelkow, N. (2007). Persuasion with Case Studies. Source: The Academy of Management Journal, 50(1), 20-24. http://doi.org/10.5465/AMJ.2007.24160882

Soni, U., Jain, V., \& Kumar, S. (2014). Measuring supply chain resilience using a deterministic modeling approach. Computers and Industrial Engineering, 74(1), 11-25. http://doi.org/10.1016/j.cie.2014.04.019

Soroka, A., Naim, M., Purvis, L., \& Hopkins, A. (2015). Supply Chain Re-shoring and its Relationship with Supply Chain Resilience, 644-655.

Stylios, C. D., \& Groumpos, P. P. (2000). Fuzzy Cognitive Maps in modeling supervisory control systems. Journal of Intelligent and Fuzzy Systems, 8(1), 8398. http://doi.org/10.1016/S0960-0779(98)00303-8

Stylios C.D., \& Groumpos P.P. (2004). Modeling Complex Systems Using Fuzzy Cognitive Maps. IEEE Transaction on Systems, Man, and Cybernetics - Part A: 
Systems and Humans, 34(1), 155-162.

Tang, C. (2006). Robust strategies for mitigating supply chain disruptions. International Journal of Logistics, 9(1), 33-45.

http://doi.org/10.1080/13675560500405584

Tsadiras, A. K. (2008). Comparing the inference capabilities of binary , trivalent and sigmoid fuzzy cognitive maps. Information Sciences, 178(20), 3880-3894. http://doi.org/10.1016/j.ins.2008.05.015

Tukamuhabwa, B. R., Stevenson, M., Busby, J., \& Zorzini, M. (2015). Supply chain resilience: definition, review and theoretical foundations for further study. International Journal of Production Research, 7543(May), 1-32. http://doi.org/10.1080/00207543.2015.1037934

Vestring, T., Rouse, T., \& Reinert, U. (2005). Hedge your offshoring bets. MIT Sloan Management Review, 46(3), 27-29. Retrieved from http://Ise.summon.serialssolutions.com/link/0/eLvHCXMwY2BQMLCwTDEHNjx Mk1IMk1NA5_okG6aYmBuZJBukGBgkgbdGh5u4e5s6Bxn7IJXmbqIMsm6ulc4e urBSMT4|JyfeAtgrMbUAbZEUY2AB9olTAU8VFy0

Wieland, A., \& Wallenburg, C. M. (2013). The influence of relational competencies on supply chain resilience: a relational view. International Journal of Physical Distribution \& Logistics Management, 43(4), 300-320. http://doi.org/10.1108/S1479-3563(2012)000012B005

Yin, R. K. (2013). Case study research: design and methods (5th ed.). London, UK: SAGE Publications, In.

Yu, R., \& Tzeng, G. H. (2006). A soft computing method for multi-criteria decision making with dependence and feedback. Applied Mathematics and Computation, 180(1), 63-75. http://doi.org/10.1016/j.amc.2005.11.163

Zailani, S. H., Subaramaniam, K. S., Iranmanesh, M., \& Shaharudin, M. R. (2015). Research on the phenomenon of supply chain resilience. International Journal of Physical Distribution \& Logistics Management, 45(7), 652-673.

Zhou, N. Y., \& Yuen, K. K. F. (2014). Towards a hybrid approach of primitive cognitive office analysis. In IEEE International Conference on Fuzzy Systems (FUZZ-IEEE) (pp. 1049-1053). Beijing, China: IEEE. 